\title{
Reduction of painful area as new possible therapeutic target in post-herpetic neuropathic pain treated with $5 \%$ lidocaine medicated plaster: a case series
}

\author{
Roberto Casale ${ }^{1,2}$ \\ Maria Di Matteo 3,7 \\ Cristina E Minella ${ }^{4,7}$ \\ Guido Fanelli ${ }^{5,7}$ \\ Massimo Allegri ${ }^{4,6,7}$ \\ 'Department of Clinical \\ Neurophysiology and Pain \\ Rehabilitation Unit, Foundation \\ Salvatore Maugeri, IRCCS, Pavia, \\ 'EFIC Montescano School, \\ Montescano, ${ }^{3}$ Anesthesia and \\ Intensive Care I, ${ }^{4}$ Pain Therapy \\ Service, Fondazione IRCCS Policlinico \\ San Matteo, Pavia, ${ }^{5}$ Department \\ of Anesthesia, Intensive Care and \\ Pain Therapy, Azienda Ospedaliera \\ Universitaria Parma, University \\ of Parma, Parma, ${ }^{6}$ Department of \\ Clinical, Surgical, Diagnostic and \\ Pediatric Science, University of Pavia, \\ Pavia, ${ }^{7}$ Study In Multidisciplinary \\ Pain Research Group, Parma, Italy
}

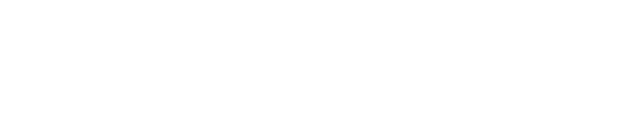

\begin{abstract}
Post-herpetic neuralgia (PHN) is neuropathic pain persisting after an acute episode of herpes zoster, and is associated with severe pain and sensory abnormalities that adversely affect the patient's quality of life and increase health care costs. Up to $83 \%$ of patients with PHN describe localized neuropathic pain, defined as "a type of neuropathic pain characterized by consistent and circumscribed area(s) of maximum pain". Topical treatments have been suggested as a first-line treatment for localized neuropathic pain. Use of 5\% lidocaine medicated plaster could reduce abnormal nervous peripheral discharge and via the plaster could have a "protective" function in the affected area. It has been suggested that use of this plaster could reduce pain as well as the size of the painful area. To evaluate this possible outcome, we retrospectively reviewed eight patients with $\mathrm{PHN}$, treated using 5\% lidocaine medicated plaster. During a follow-up period of 3 months, we observed good pain relief, which was associated with a $46 \%$ reduction in size of the painful area after one month (from $236.38 \pm 140.34 \mathrm{~cm}^{2}$ to $\left.128.80 \pm 95.7 \mathrm{~cm}^{2}\right)$ and a $66 \%$ reduction after 3 months $\left(81.38 \pm 59.19 \mathrm{~cm}^{2}\right)$. Our study cohort was composed mainly of elderly patients taking multiple drugs to treat comorbidities, who have a high risk of drug-drug interactions. Such patients benefit greatly from topical treatment of PHN. Our observations confirm the effectiveness of lidocaine plasters in the treatment of $\mathrm{PHN}$, indicating that $5 \%$ lidocaine medicated plaster could reduce the size of the painful area. This last observation has to be confirmed and the mechanisms clarified in appropriate larger randomized controlled trials.
\end{abstract}

Keywords: localized neuropathic pain, topical treatment, chronic pain, drug-drug interactions, patient's outcome

\section{Introduction}

Neuropathic pain, defined as "pain arising as a direct consequence of a lesion or a disease affecting the somatosensory system", ${ }^{1}$ is a disorder that can considerably affect quality of life for patients. Even though up to $5 \%$ of the general population could be involved, treatment of neuropathic pain continues to be challenging due to the inadequate effectiveness of systemic therapies and their frequent central side effects. ${ }^{2}$

In the wide area of peripheral neuropathic pain, the identification of specific neuropathic pain syndromes that affect only a circumscribed area of the body may drive a clinical decision to use targeted localized treatment(s). Recently, Mick et al proposed defining all peripheral neuropathic pain "characterized by consistent and circumscribed area(s) of maximum pain associated with negative or positive sensory signs"3
Correspondence: Massimo Allegri Department of Clinical, Surgical, Diagnostic and Pediatric Science, University of Pavia, San Matteo Hospital, Via le Golgi 19, 27 I00 Pavia, Italy

Tel +390382502627

Fax +39038250 2226

Email massimo.allegri@unipv.it 
as localized neuropathic pain (LNP). According to the relevant guidelines, ${ }^{4-6} 5 \%$ lidocaine medicated plaster could be considered as a first-line treatment option for LNP due to its good efficacy and safety profile, especially in elderly patients where comorbidities are quite often present and polypharmacy is poorly tolerated.

Up to $83 \%$ of patients with post-herpetic neuralgia (PHN) complain of an LNP syndrome, ${ }^{3}$ for which $5 \%$ lidocaine medicated plaster showed better effectiveness versus placebo ${ }^{7,8}$ and substantially better pain relief than pregabalin, ${ }^{9,10}$ with fewer systemic side effects even in longterm treatment. ${ }^{11-13}$

Several different mechanisms sustain PHN, ${ }^{14}$ including peripheral inflammation, nerve damage and denervation, and peripheral and central sensitization. Lidocaine acts by blocking abnormally functioning (sensitized) Nav 1.7 and Nav 1.8 sodium channels in dermal nociceptors, ${ }^{15}$ thereby reducing ectopic discharges, which raise the peripheral ectopic discharge threshold. ${ }^{15}$ Topical 5\% lidocaine plaster does not affect A-beta fibers, so does not cause any paresthesia and/or numbness. ${ }^{16}$ Finally, a passive protective action of the plaster itself has been reported. ${ }^{8-10}$

In a cohort of patients with LNP due to nerve trauma, ${ }^{17}$ $5 \%$ lidocaine medicated plaster showed optimal efficacy in reducing pain and the size of the painful area. To our knowledge, no other structured trial has investigated this possible "new" endpoint in PHN patients. In our first eight PHN patients treated with Versatis 5\% plaster (Grunenthal, Germany) (the drug was approved in Italy in May 2013), we investigated whether it could be helpful both in reducing pain and allodinic (static and/or dynamic) areas. Allodynia is a phenomenon in which normally nonpainful stimuli are perceived as painful, and can be a clinical sign of peripheral and central sensitization. The two components can be differentiated using different types of stimuli, ie, peripheral sensitization can be evoked by static mechanical stimulation (static mechanical allodynia) whereas allodynia to dynamic mechanical stimulation is the result of central sensitization. While the static component is only found in the injured area, the dynamic component also extends into the halo of undamaged tissue surrounding the injury. ${ }^{18}$

\section{Case series}

Consistent with the literature and following approval in Italy, $5 \%$ lidocaine medicated plaster was used in a group of PHN patients with untreated LNP, LNP that was inadequately controlled, or side effects from systemic drugs. Following our hospital administrative rules, all patients signed an informed consent allowing anonymous use of their clinical data for research purposes. In accordance with our clinical practice, the patients were screened at the first visit and then followed up after 15, 30, and 90 days. Patients could telephone and ask for another consultation if they experienced side effects or inadequate analgesia.

At all visits, we recorded: daily pain intensity (mean, least, and worst, using the Numeric Rating Scale); paresthesia and dynamic allodynia (scale 0 [none] to 5 [worst imaginable]); and static allodynia with the Von Frey hair test (caliber from 0 [worst allodynia] to 18 [normal sensation] of Von Frey monofilaments perceived as painful - less is the caliber perceived as painful, greater is the static allodynia). Percentage pain relief was also recorded. We used a well established Von Frey hair set (Touch Test ${ }^{\mathrm{TM}}$ sensory evaluators; North Coast Medical, Inc. Morgan Hill, CA, USA), with a 5.07 caliper corresponding to $10 \mathrm{~g}$ applied for 1.5 seconds, which delivers a clear mechanical suprathreshold nonpainful stimulus. The area of statical tactile allodynic area was measured in $\mathrm{cm}^{2}$.

During their first visit, patients were instructed regarding how to apply the 5\% lidocaine medicated plaster to the most painful areas of intact skin; they were allowed to use a maximum of three plasters for 12 hours a day. Depending on the clinical results seen during follow-up, we reduced their systemic analgesic medication if good pain relief (of at least 30\%) was achieved. The data reported here are the results of a 3-month follow up.

Eight patients with PHN LNP (five men and three women) were observed from May to September 2013. Their mean age was $77.75 \pm 7.10$ (range 69-89) years and mean Body Mass Index (BMI) was $28.1 \pm 5.5 \mathrm{~kg} / \mathrm{m}^{2}$. The acute episode of herpes zoster had occurred at a mean of $3.7 \pm 3.6$ years earlier. The rash affected the trunk in all cases, except for one patient whose left hand was affected. All patients were on polypharmacy, taking a mean of $4 \pm 2$ nonanalgesic drugs for comorbid conditions.

All patients reported having tried at least one systemic drug for pain relief (antidepressant, anticonvulsant, and/or opioids) with inadequate pain control (five patients) or good pain control but severe side effects (three patients). One patient reported an accidental fall with a rib fracture due to dizziness on anticonvulsant treatment.

The patients reported good pain relief $(45.00 \% \pm 19.75 \%)$ as early as 2 weeks after the start of topical therapy, with further improvement as treatment continued $(52.00 \% \pm 23.87 \%$ by month 1 and $60.00 \% \pm 18.70 \%$ by month 3 ), and reduction/ cessation of systemic treatment in six patients (Table 1). Paresthesia and dynamic allodynia decreased significantly at 
Table I Evolution of systemic therapy for each patient before and after introduction of topical lidocaine

\begin{tabular}{|c|c|c|}
\hline Patient & Baseline oral therapy & Final oral therapy \\
\hline \multirow[t]{3}{*}{ I } & Tapentadol $100 \mathrm{mg} \times 2$ & Tapentadol 100 mg \\
\hline & Pregabalin 175 mg ×2 & Pregabalin $100 \mathrm{mg}+75 \mathrm{mg}$ \\
\hline & Duloxetine $60 \mathrm{mg}$ & Duloxetine $60 \mathrm{mg}$ \\
\hline \multirow[t]{4}{*}{2} & Tramadol/paracetamol & Tramadol/paracetamol \\
\hline & $37.5 / 325 \mathrm{mg} \times 2$ and & $37.5 / 325 \mathrm{mg}$ only as \\
\hline & tramadol/paracetamol & needed \\
\hline & $37.5 / 325 \mathrm{mg}$ as needed & \\
\hline 3 & Tapentadol $150 \mathrm{mg} \times 2$ & Tapentadol $150 \mathrm{mg} \times 2$ \\
\hline 4 & Clonazepam $0.5 \mathrm{mg}$ & Clonazepam $0.5 \mathrm{mg}$ \\
\hline \multirow[t]{2}{*}{5} & Pregabalin $75 \mathrm{mg} \times 2$ & Paracetamol I g only as \\
\hline & & needed \\
\hline 6 & Tapentadol $50 \mathrm{mg} \times 2$ & Nothing \\
\hline \multirow[t]{3}{*}{7} & Pregabalin $75 \mathrm{mg}$ and & Nothing \\
\hline & tramadol/paracetamol & \\
\hline & $37.5 / 325 \mathrm{mg}$ as needed & \\
\hline 8 & $\begin{array}{l}\text { Paracetamol I } \mathrm{g} \times 2 \text { and } \\
\text { paracetamol I } \mathrm{g} \text { as needed }\end{array}$ & $\begin{array}{l}\text { Paracetamol I } g \text { only as } \\
\text { needed }\end{array}$ \\
\hline
\end{tabular}

3 months from $2.88 \pm 1.64$ to $1.20 \pm 1.10$ and from $3.75 \pm 0.71$ to $1.80 \pm 1.64$, respectively. We observed a similarly consistent reduction in static allodynia from $8.63 \pm 3.58$ to $14.00 \pm 0.82$ over 3 months.

The allodynic (static or dynamic) area was measured in five of eight patients with thoracic PHN (Figure 1A). The area became progressively smaller from a baseline measurement of $236.38 \pm 140.34 \mathrm{~cm}^{2}$ to $128.80 \pm 95.7 \mathrm{~cm}^{2}$ after one month (46\% reduction, $P=0.129$ ) and to $81.38 \pm 59.19 \mathrm{~cm}^{2}$ after 3 months (66\% reduction, $P=0.02)$. With the reduction in size of the area, patients were able to apply fewer and smaller plasters. A more pronounced reduction was observed in the height $(50 \%)$ than in the length $(33 \%)$ of the affected area (Figure 1B).

\section{Discussion}

Neuropathic pain continues to be a challenging clinical problem. ${ }^{2}$ People with neuropathic pain are often elderly and may have several comorbidities and a high risk of drug-drug interactions, which presents a serious limitation to therapy. ${ }^{19}$ To achieve good pain relief, it is often necessary to give a combination of two or more drugs, ${ }^{20}$ which increases the risk of drug-drug interactions and side effects.

The mainstay of treatment for neuropathic pain is still adequate personalized therapy based on an understanding of the pain pathophysiology and the patient's clinical features. ${ }^{21}$ The majority of patients evaluated in our case series complained of the limited effectiveness of pain treatments and/ or side effects from systemic treatment for PHN, and had had their pain for several months or years.
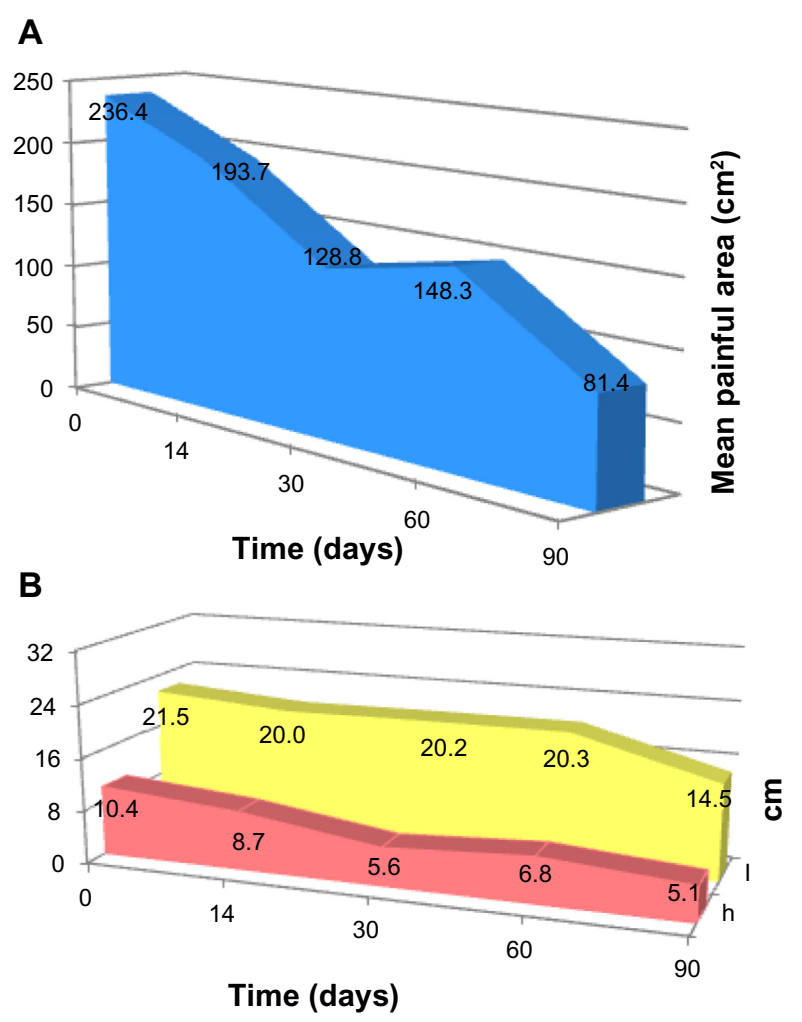

$\because \mathrm{h} \quad \mathrm{I}$

Figure I (A) Reduction of the whole allodynic area and (B) reduction of the height (h) and length (I) of the same area.

When patient refers a LNP, correctly diagnosed according to validated diagnostic algorithm, ${ }^{22}$ more recent guidelines ${ }^{4,5}$ suggest topical products as the first-line therapeutic option since they are better tolerated, have no or few systemic effects and drug-drug interactions, and have better patient compliance. ${ }^{9,10,23,24}$ Our case series reflects all these common clinical aspects.

The main mechanism of the therapeutic action of lidocaine is blockade of voltage-gated sodium channels. ${ }^{15,25}$ However, topical lidocaine may have other peripheral actions through a desensitizing effect of TRPA1 channels, contributing to its "nonanesthetic analgesic" effects. ${ }^{26}$ Thus, the reduction in peripheral sensitization could be attributed to both blockade of pathological sodium channel expression and desensitization of TRPA1 channels.

A characteristic feature of $\mathrm{PHN}$ is the presence of an area of primary hyperalgesia (static mechanical and thermal allodynia within the damaged area) and secondary hyperalgesia (dynamic mechanical allodynia that surrounds the first area). ${ }^{27}$ The static mechanical allodynia is mainly mediated by sensitized peripheral nociceptors, while the dynamic component is probably a consequence of altered processing of large diameter primary afferent inputs in 
the central nervous system. These alterations are at least partially maintained by the barrage of nociceptor activity from both normal and abnormal inputs. ${ }^{27}$ The importance of ongoing activity to maintain the secondary hyperalgesia has not been completely elucidated, even though in patients with neuropathic pain, secondary hyperalgesia and allodynia have been seen to be critically dependent on continuous afferent input. ${ }^{18}$

Hence, 5\% lidocaine medicated plaster could act by adding blockade of pathological sodium and TRPV1 channels to the reduction of mechanical noxious/non-noxious inputs via the protective action of the plaster. This reduction of peripheral inputs could contribute to reducing both primary and secondary sensitization, and consequently the size of the painful area, ${ }^{28,29}$ as also suggested by a healthy volunteer study. ${ }^{30}$

In our study, the mean size of the painful area was $236.38 \pm 140.34 \mathrm{~cm}^{2}$, which is in agreement with data in the literature. ${ }^{31}$ Regarding the reduction of the static allodynic area, we noticed that there is a much greater reduction of the height (number of metameres involved) rather than of the length (area of the same nerve involved) of the painful area. In PHN, the secondary hyperalgesic area is mainly distributed above and below the primary painful area in the dermatome where an overlapping of innervation is anatomically present. It could be arguable that if neural plasticity can be induced by treatment, it may be more evident in peripheral areas of secondary hyperalgesia. ${ }^{18}$

Hence this treatment could have another important clinical effect: the reduction of the allodynic area, as also suggested in a study about LNP with recent onset. ${ }^{17}$ In fact, a more than $50 \%$ reduction in the size of the painful area was recorded, even though the patients had been complaining of PHN for several months or years.

This study has several limitations. Due to the small number of patients, it was not possible to evaluate if the reduction in size of the painful area was related to the time of onset of PHN or to the more pronounced reduction of static rather than dynamic allodynia. Nevertheless, our case series highlights a possible role of chronic topical treatment not only in treating LNP but also in reducing the size of the painful area. These data have to be confirmed by appropriately designed controlled trials investigating this endpoint as well as the mechanisms for the activity of $5 \%$ lidocaine medicated plaster, ie, whether it acts more on primary rather than secondary hyperalgesia, and whether the time of onset of PHN/LNP could be a predictive factor of efficacy.

\section{Disclosure}

$\mathrm{RC}$ has been a speaker for and received research support from Grünenthal. MA has been a speaker for Grünenthal. No funding or sponsorship was involved in this study.

\section{References}

1. Treede RD, Jensen TS, Campbell JN, et al. Neuropathic pain redefinition and a grading system for clinical and research purposes. Neurology. 2008;70(18):1630-1635.

2. O'Connor AB, Dworkin RH. Treatment of neuropathic pain: an overview of recent guidelines. Am J Med. 2009;122(Suppl 10):S22-S32.

3. Mick G, Baron R, Finnerup NB, et al. What is localized neuropathic pain? A first proposal to characterize and define a widely used term. Pain Manag. 2012;2(1):71-77.

4. Finnerup NB, Otto M, McQuay HJ, Jensen TS, Sindrup SH. Algorithm for neuropathic pain treatment: an evidence based proposal. Pain. 2005;118(3):289-305.

5. Attal N, Cruccu G, Baron R, et al. EFNS guidelines on the pharmacological treatment of neuropathic pain: 2010 revision. Eur $J$ Neurol. 2010;17(9):1113-e88.

6. Dworkin RH, O'Connor AB, Audette J, et al. Recommendations for the pharmacological management of neuropathic pain: an overview and literature update. Mayo Clin Proc. 2010;85(Suppl 3):S3-S14.

7. Meier T, Wasner G, Faust M, et al. Efficacy of lidocaine patch $5 \%$ in the treatment of focal peripheral neuropathic pain syndromes: a randomized, double-blind, placebo-controlled study. Pain. 2003;106(1-2): 151-158.

8. Binder A, Bruxelle J, Rogers P, et al. Topical 5\% lidocaine (lignocaine) medicated plaster treatment for post-herpetic neuralgia: results of a double-blind, placebo-controlled, multinational efficacy and safety trial. Clin Drug Investig. 2009;29(6):393-408.

9. Rehm S, Binder A, Baron R. Post-herpetic neuralgia: $5 \%$ lidocaine medicated plaster, pregabalin, or a combination of both? A randomized, open, clinical effectiveness study. Curr Med Res Opin. 2010;26(7): $1607-1619$.

10. Baron R, Mayoral V, Leijon G, et al. 5\% lidocaine medicated plaster versus pregabalin in post-herpetic neuralgia and diabetic polyneuropathy: an open-label, non-inferiority two-stage RCT study. Curr Med Res Opin. 2009;25(7):1663-1676.

11. Hans G, Sabatowski R, Binder A, et al. Efficacy and tolerability of a $5 \%$ lidocaine medicated plaster for the topical treatment of postherpetic neuralgia: results of a long-term study. Curr Med Res Opin. 2009;25(5):1295-1305.

12. Pickering G, Pereira B, Clère F, et al. Cognitive function in older patients with postherpetic neuralgia. Pain Pract. 2014;14(1):E1-E7.

13. Sabatowski R, Hans G, Tacken I, et al. Safety and efficacy outcomes of long-term treatment up to 4 years with $5 \%$ lidocaine medicated plaster in patients with post-herpetic neuralgia. Curr Med Res Opin. 2012;28(8): 1337-1346.

14. Johnson RW, Wasner G, Saddier P, Baron R. Postherpetic neuralgia: epidemiology, pathophysiology and management. Expert Rev Neurother. 2007;7(11):1581-1595.

15. Liu M, Wood JN. The roles of sodium channels in nociception: implications for mechanisms of neuropathic pain. Pain Med. 2011; 12 Suppl 3:S93-S99.

16. Gammaitoni AR, Alvarez NA, Galer BS. Safety and tolerability of the lidocaine patch $5 \%$, a targeted peripheral analgesic: a review of the literature. J Clin Pharmacol. 2003;43(2):111-117.

17. Correa-Illanes G, Roa R, Piñeros JL, Calderón W. Use of 5\% lidocaine medicated plaster to treat localized neuropathic pain secondary to traumatic injury of peripheral nerves. Local Reg Anesth. 2012;5: 47-53.

18. Koltzenburg M, Lundberg LE, Torebjörk HE. Dynamic and static components of mechanical hyperalgesia in human hairy skin. Pain. 1992;51(2):207-219. 
19. Jensen TS, Madsen CS, Finnerup NB. Pharmacology and treatment of neuropathic pains. Curr Opin Neurol. 2009;22(5):467-474.

20. Chaparro LE, Wiffen PJ, Moore RA, Gilron I. Combination pharmacotherapy for the treatment of neuropathic pain in adults. Cochrane Database Syst Rev. 2012;7:CD008943.

21. Allegri M, Clark MR, De Andrés J, Jensen TS. Acute and chronic pain: where we are and where we have to go. Minerva Anestesiol. 2012;78(2): 222-235.

22. Casale R, Mattia C. Building a diagnostic algorithm on localized neuropathic pain (LNP) and targeted topical treatment: focus on 5\% lidocaine medicated plaster. Ther Clin Risk Manag. 2014;10:259-268.

23. Brix Finnerup N, Hein Sindrup S, Staehelin Jensen T. Management of painful neuropathies. Handb Clin Neurol. 2013;115:279-290.

24. Clère F, Delorme-Morin C, George B, et al. 5\% lidocaine medicated plaster in elderly patients with postherpetic neuralgia: results of a compassionate use programme in France. Drugs Aging. 2011;28(9): 693-702.

25. Sheets PL, Jarecki BW, Cummins TR. Lidocaine reduces the transition to slow inactivation in $\mathrm{Na}(\mathrm{v}) 1.7$ voltage-gated sodium channels. Br J Pharmacol. 2011;164(2b):719-730.
26. Leffler A, Lattrell A, Kronewald S, Niedermirtl F, Nau C. Activation of TRPA1 by membrane permeable local anesthetics. Mol Pain. 2011;7:62.

27. Treede RD, Davis KD, Campbell JN, Raja SN. The plasticity of cutaneous hyperalgesia during sympathetic ganglion blockade in patients with neuropathic pain. Brain. 1992;115 Pt 2:607-621.

28. Woolf CJ, Salter MW. Neuronal plasticity: increasing the gain in pain. Science. 2000;288(5472):1765-1769.

29. Baron R, Hans G, Dickenson AH. Peripheral input and its importance for central sensitization. Ann Neurol. 2013;74(5):630-636.

30. Gustorff B, Hauer D, Thaler J, Seis A, Draxler J. Antihyperalgesic efficacy of 5\% lidocaine medicated plaster in capsaicin and sunburn pain models - two randomized, double-blinded, placebo-controlled crossover trials in healthy volunteers. Expert Opin Pharmacother. 2011;12(18):2781-2790.

31. Rowbotham MC, Davies PS, Verkempinck C, Galer BS. Lidocaine patch: double-blind controlled study of a new treatment method for post-herpetic neuralgia. Pain. 1996;65(1):39-44.
Journal of Pain Research

\section{Publish your work in this journal}

The Journal of Pain Research is an international, peer-reviewed, open access, online journal that welcomes laboratory and clinical findings in the fields of pain research and the prevention and management of pain. Original research, reviews, symposium reports, hypothesis formation and commentaries are all considered for publication.

\section{Dovepress}

The manuscript management system is completely online and includes a very quick and fair peer-review system, which is all easy to use. Visit http://www.dovepress.com/testimonials.php to read real quotes from published authors. 